\title{
Mechanisms of Neural Cell Death: Implications for Development of Neuroprotective Treatment Strategies
}

\author{
Alexander G. Yakovlev and Alan I. Faden \\ Department of Neuroscience, Georgetown University Medical Center, Washington, DC 20057
}

\begin{abstract}
Summary: It has been increasingly recognized that cell death phenotypes and their molecular mechanisms are highly diverse. Necrosis is no longer considered a single entity, passively mediated by energy failure. Moreover, caspase-dependent apoptosis is not the only pathway involved in programmed cell death or even the only apoptotic mechanism. Recent experimental work emphasizes the diverse and interrelated nature of cell death mechanisms. Thus, there are both caspase-dependent and caspase-independent forms of apoptosis, which may differ morphologically as well as mechanistically. There are also necrotic-like phenotypes that require de novo protein synthesis and are, therefore, forms of programmed cell death. In addition,
\end{abstract}

forms of cell death showing certain morphological features of both necrosis and apoptosis have been identified, leading to the term aponecrosis. Considerable experimental evidence also shows that modulation of one form of cell death may lead to another. Together, these observations underscore the need to substantially revise our conceptions about neuroprotection strategies. Use of multiple treatments that target different cell death cascades, or single agents that moderate multiple cell death pathways, is likely to lead to more effective neuroprotection for clinical disorders. Key Words: Apoptosis, necrosis, caspase, calpain, AIF.

\section{INTRODUCTION}

Neuronal loss occurs as an essential feature of normal CNS development, as well as in acute or chronic neurodegenerative disorders. ${ }^{1-4}$ It has long been recognized that a variety of factors can trigger secondary auto-destructive reactions within the CNS, including free radicals, excitatory amino acids, eicosanoids, lipid degradation products, tissue cations, inflammation, and immune responses. ${ }^{5,6}$ These secondary injury factors are released or activated over a period from seconds (e.g., lipid, cation changes) to days (e.g., inflammatory, immune responses) after the primary insult and may act either sequentially or in parallel to cause delayed or expanding cell death. Detailed reviews of delayed injury processes/ mechanisms can be found elsewhere., 5 Depending on developmental age, injury severity, or a specific cell type, injury factors can trigger alternative mechanisms of cell death. ${ }^{7}$

The focus of research on secondary brain injury has historically been on mechanisms related to necrosis. This

Address correspondence and reprint requests to Alan I. Faden, M.D., Department of Neuroscience, Georgetown University Medical Center, 3970 Reservoir Road NW, Room EP-12, Washington, DC 20057.

E-mail: fadena@georgetown.edu. has led to the evaluation of numerous pharmacological strategies, including calcium channel blockers, corticosteroids and antioxidants, glutamate receptor antagonists, opioid receptor antagonists, thyrotropin-releasing hormone analogs, and magnesium administration, as well as various anti-inflammatory and immune modulatory treatments. ${ }^{8}$ Although several of these strategies have shown modest benefits in the treatment of acute spinal cord injury in humans, ${ }^{9,10}$ neuroprotection studies in head injury and stroke have been disappointing. In part, this may reflect flaws in trial design or failure to more directly parallel pre-clinical and clinical studies ${ }^{11,12}$; however, to a significant degree, such negative trials may result from conceptual difficulties, namely a failure to appreciate the complexity of cell death phenotypes and mechanisms.

\section{CELL DEATH PHENOTYPES}

Nomenclature relating to the cell death phenotypes has been confusing. One of the early attempts to classify cell death phenotypes, based upon morphological analyses in developmental models, was made by Schweichel and Merker, ${ }^{13}$ who identified three types of cell death (types 1,2 , and 3 ). Type 1 is manifested by nuclear condensa- 
tion and pyknosis, reduced cytoplasmic volume, late cell fragmentation, and phagocytosis. Type 2, or autophagic degeneration, is characterized by substantial autophagic vacuolization in the cytoplasm. Type 3 , or cytoplasmic cell death, is characterized by general disintegration and deletion of organelles. Features of type 1 cell death appear identical to those classically identified by Kerr as apoptosis. ${ }^{14}$ Types 2 and 3 show features associated with necrosis ${ }^{15}$; in 1990 , this classification was recapitulated and refined by Clarke, ${ }^{16}$ who distinguished two subtypes of cytoplasmic cell death, 3A non-lysosomal disintegration and 3B cytoplasmic. Additional morphological forms have been described, but it has been suggested that these may reflect different cell types or initiating stimuli rather than fundamentally different cellular mechanisms. ${ }^{17}$ Further details regarding these morphological classifications can be found in several excellent reviews. ${ }^{15,17,18}$

More recent studies have focused on the roles of apoptosis versus necrosis in neuronal loss associated with acute or chronic neurodegenerative disorders. Apoptosis and necrosis have been distinguished by various histological and biochemical criteria. Thus, necrosis is characterized by loss of membrane integrity and cellular swelling, damage to organelles, lysosomal disruption, and uncontrolled cell lysis that often leads to tissue inflammation. ${ }^{19}$ In contrast, typical features of apoptotic cells include preserved membrane integrity and cell shrinkage, cytoplasmic and nuclear condensation, and plasma membrane blebbing. At later stages of apoptosis, cells may disintegrate into apoptotic bodies, which are engulfed by neighboring cells. Moreover, it does not lead to an inflammatory response. ${ }^{19}$

Although such morphological differences have been widely used to distinguish these two types of cell death, some pathologists have suggested a modified nomenclature. Thus, the Society of Toxicologic Pathologists proposed use of the term "necrosis" to describe cell death independent of a specific pathway, with "oncosis" used to reflect cell swelling as may occur with acute ischemia and "apoptotic" as a modifier of cell death ("necrosis") showing apoptotic features as described above. ${ }^{20}$ However, apoptosis and necrosis may, in fact, share certain common signal transduction pathways and cooperate in cell death. ${ }^{21}$ Indeed, apoptosis and necrosis may be induced by the same insult, with the magnitude of the insult determining the decision of the cell to undergo one of the alternative cell death pathways. ${ }^{22}$ Intracellular ATP levels appear to be an important factor in the initiation of apoptotic or necrotic execution programs. ${ }^{23,24}$ Moreover, inhibition of one of these cell death pathways may increase cell loss through the other. ${ }^{7,25}$

Recent studies have further complicated the classification of cell death phenotypes, as well as the mechanisms involved. ${ }^{21}$ Careful morphological analyses of dy- ing neurons in mouse models of Huntington's disease and amyotrophic lateral sclerosis failed to identify either classical necrosis or apoptosis ${ }^{24,26}$ but rather revealed features more consistent with an alternative type of neuronal cell death that has been termed paratosis. ${ }^{27}$ This type of neuronal death requires gene expression, displays non-apoptotic morphology with vacuolization, and is independent of caspase activation. Whether this form of cell death should be characterized within the existing nomenclature as type 2 or $3 \mathrm{~B}$ is uncertain, ${ }^{28}$ but many descriptions of non-apoptotic cell death showing cytoplasmic vacuolization appear to be most closely related to type $3 \mathrm{~B} .{ }^{27} \mathrm{In}$ addition, forms of apoptosis with nonclassical morphological features and different biochemical markers have been identified. ${ }^{29}$ Thus, there appear to be multiple forms of programmed cell death, with different morphological features and likely distinct molecular mechanisms (FIG. 1). Recognition of this diversity has substantial implications for the development of more effective neuroprotective strategies.

\section{CASPASE-DEPENDENT APOPTOSIS}

The apoptotic machinery initially identified in Caenorhabditis elegans is evolutionarily conserved in higher organisms. ${ }^{30}$ Programmed cell death in this nematode is largely controlled by two pro-apoptotic genes (ced-3 and ced-4) and one anti-apoptotic gene (ced-9). Although molecular mechanisms controlling apoptosis in mammals are far more complex, homologs for ced-3 (caspases), ced-4 [apoptosis protease activating factor-1 (apaf-1)], and ced-9 (bcl-2) have been identified. ${ }^{29}$ The term "caspase" refers to cysteinyl aspartic acid-proteases. ${ }^{31}$ Caspases share considerable sequence identity around the putative active site cysteine: QAC(R/A/ $\mathrm{G}) \mathrm{G}^{31}$ These enzymes are translated as zymogen proforms that include an N-terminal prodomain, a large subunit, and a C-terminal small subunit, which are separated by specific caspase recognition sites. Processing of caspase precursors at these sites leads to their activation. Active caspases are heterotetramers consisting of two large and two small subunits. Upon activation, caspases may cleave their own precursors or other procaspases, resulting in a caspase activation cascade.

Most caspase substrates are cleaved by these proteases after aspartate at P1; however, some exceptions to the rule have also been reported. ${ }^{32}$ Variability in the P2-P4 region determines substrate specificity for individual members of the family. Based on their substrate specificity, caspases have been divided into group I (caspase-1, -4, and -5, which prefer the tetrapeptide sequence WEHD), group II (caspase-2, -3 , and -7 , which preferentially cleave DEXD), and group III (caspase-6, -8 , and -9 , which prefer (L/V)EXD). ${ }^{31}$

Based on mechanisms of activation, caspases have 


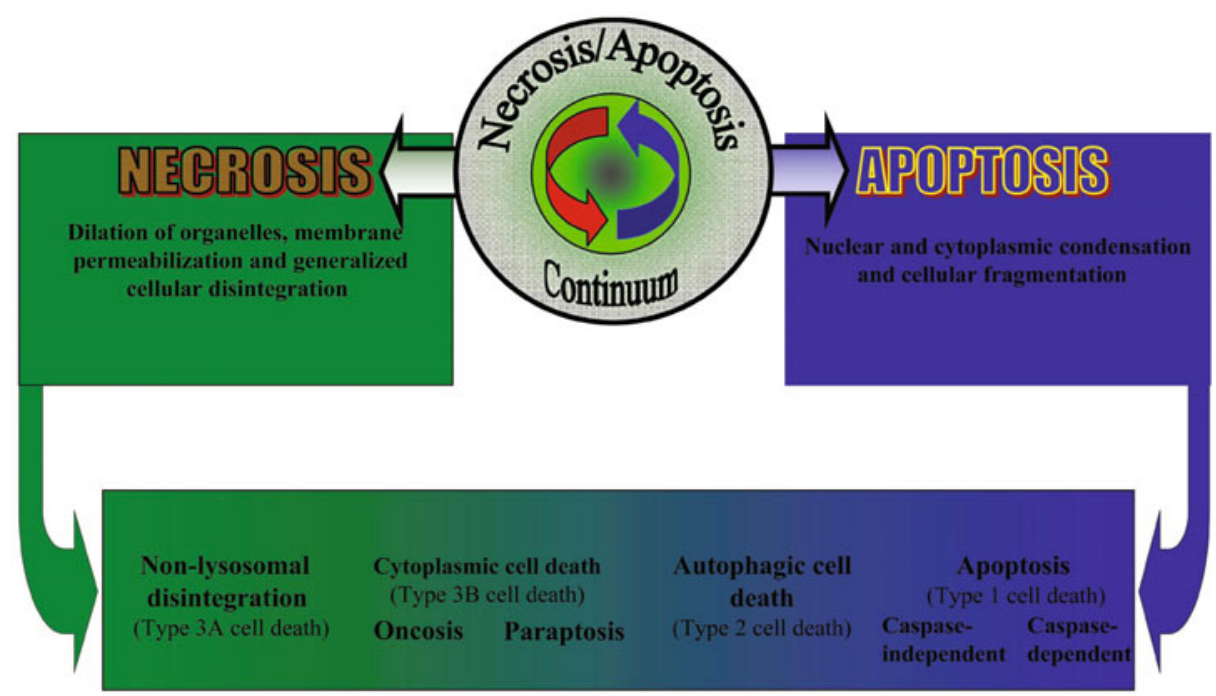

FIG. 1. Apoptosis-necrosis continuum. Cell death includes morphologically distinct types that have been characterized in various ways. No single classification encompasses all of the variant descriptions in the literature. Clearly, there is a continuum of cell death variants, with multiple variants coexisting in both clinical disorders and clinically relevant experimental models. Here we depict an apoptosisnecrosis continuum leading to cell death with different morphological features.

been divided into initiators and effectors. The initiator caspases, such as caspase- 8 and -9 , begin the disassembly process and activate downstream effector caspase-3, -6 , and -7 , leading to an amplified caspase cascade. ${ }^{33}$ Active effector caspases contribute to the morphological and biochemical manifestation of apoptotic death, such as membrane blebbing, condensation or margination of chromatin and nuclear fragmentation, as well as alterations in activity of numerous nuclear and cytosolic enzymes. Unlike effector caspases, initiator caspases have a long N-terminal prodomain, do not undergo autoactivation, and do not cleave one another. For activation they require additional proteins, such as death domain-containing receptors (type I apoptosis) or functional apoptosomes (type II apoptosis). ${ }^{1}$

A third group of mammalian caspases, which includes caspase-1, -4, -5, -11, -12, and -13, has been defined in terms of their function as pro-inflammatory enzymes. In contrast to the effector caspases that are involved in the execution of the apoptotic process, pro-inflammatory caspases are poor substrates for other caspases, and their apical activation pathways are poorly understood.

\section{Pathways of caspase- 3 activation}

Of the 14 caspases identified in mammals, caspase- 3 appears to be the major effector in neuronal apoptosis triggered by various stimuli. Strong evidence supporting the specific role for this protease comes from studies on caspase-3 knockout mice, in which brain development is profoundly altered. ${ }^{34}$ A role for caspase- 3 in injury-induced neuronal loss was subsequently established using semi-specific peptide caspase inhibitors in vivo and in vitro. ${ }^{35}$

Two major caspase-3 activating pathways have been identified: an extrinsic pathway involving cell-surface receptors, and an intrinsic pathway resulting from alterations at the level of the mitochondrion and activation of the apoptosome. ${ }^{1}$ The extrinsic pathway requires oligomerization of "death" receptors and the formation of death-inducing signaling complex. ${ }^{35}$ This process is regulated by members of the tumor necrosis factor (TNF) family of cytokines that include Fas ligand (Apo-1/CD95 ligand), TNF- $\alpha$, TNF-related apoptosis-inducing ligand, and TNF-related weak inducer of apoptosis. ${ }^{35,36}$ Oligomerization of a death receptor leads to binding of its intracellular domain to the adaptor molecule Fas-associated death domain or caspase and RIP adaptor with death domain, which recruits initiator procaspase- 8 and triggers its activation. The released active caspase- 8 activates downstream executioner caspases-3 and -7. In addition, activated caspase- 3 may cleave procaspase- $8,{ }^{37}$ thereby amplifying the death process. Initiation of apoptosis through the extrinsic pathway does not usually require new mRNA or protein synthesis.

In some cell types caspase- 8 triggers the intrinsic apoptotic pathway by cleaving cytosolic Bid, a pro-apoptotic member of the Bcl-2 family. The C-terminal portion of Bid translocates to the outer mitochondrial membrane and triggers the release of cytochrome $c$ from mitochondria to the cytoplasm. ${ }^{38}$ In the presence of ATP or dATP, cytochrome $c$ binds to Apaf- 1 and allows the recruitment and activation of procaspase- 9 within the apoptosome. ${ }^{35}$ Caspase- 9 cleaves and activates executioner caspases-3 and -7 . Active caspase- 3 can cleave and activate at least four other caspases $(-2,-6,-8$, and -10$)$ and also participates in a feedback amplification loop involving caspase- $9 .^{37}$ 
In contrast to the extrinsic pathway, initiation of the intrinsic apoptotic cascade in specific cell types often requires gene induction and protein synthesis, where an essential role has been attributed to p53 and pro-apoptotic members of Bcl-2 family. ${ }^{35,39}$ However, precise mechanisms by which gene activation signals Bcl-2 family proteins remain to be elucidated.

Numerous reports support an essential role for the intrinsic caspase pathway in neuronal apoptosis after cerebral ischemia, brain trauma, spinal cord injury, Huntington's disease, Alzheimer's disease, and seizures. ${ }^{1,4,35,40}$ Moreover, similar to caspase-3 knockout mice, null mutants of caspase- 9 show severe defects of programmed cell death in the nervous system. ${ }^{41}$ The majority of these mutants are embryonic lethal or die shortly after birth. A general reduction of neuronal death is found in their embryonic brain tissue; however, the phenotype of caspase- $9^{-1-}$ mice is more severe than that of caspase- $3^{-1-}$, which suggests that caspases other than caspase-3 (such as caspase-7) may also function downstream from caspase- $9 .{ }^{41}$ Furthermore, insertional mutagenesis or targeted disruption of apaf-1 gene also produces perinatal lethality that is associated with marked developmental abnormalities. Apaf- $1^{-1-}$ cells fail to activate caspase- 3 through the intrinsic pathway of apoptosis in vivo or in vitro, which presumably accounts for similar developmental abnormalities seen in Apaf-1-, caspase-9-, and caspase-3-deficient embryos. ${ }^{34,41}$ This suggests that activation of procaspase- 3 by the apoptosome-mediated pathway plays a critical role in neuronal apoptosis at early stages of brain development.

\section{Modulation of caspase activation}

Caspase activation can be modulated at many critical steps. For example, the anti-apoptotic Bcl-xL protein ${ }^{42}$ acts as a major inhibitor of cytochrome c-mediated caspase activation; transgenic mice lacking $b c l-x$ die in embryonic development and show increased death of post-mitotic neurons. ${ }^{43}$

Initially, it has been suggested that Bcl-xL directly binds to Apaf-1, thus preventing activation of caspase-9. However, recent studies demonstrate that intracellular localization of Apaf- $\mathrm{H}^{44}$ differs from that of Bcl- $\mathrm{xL}^{45}$ and indicate that $\mathrm{Bcl}-\mathrm{xL}$, like other anti-apoptotic members of the Bcl-2 family, is involved in the control of permeability of mitochondrial membranes and the release of cytochrome $c$ via interaction with $\mathrm{Bax}^{46}$ On the other hand, Bcl-xL can be cleaved by caspases, and the resulting $\mathrm{C}$-terminal fragment of Bcl-xL potently induces apoptosis. $^{47}$

Bax is another member of the Bcl-2 family found to promote apoptosis. Under normal conditions, Bax predominantly localizes in the cytosol but translocates to mitochondrial and other membranes early in apoptosis. ${ }^{48}$ Once translocated to mitochondria, Bax forms homo- oligomers, leading to loss of mitochondrial membrane potential, cytochrome $c$ release, formation of the apoptosome complex, and caspase activation. ${ }^{49}$ Bax deficiency does not cause hyperplasia or malformations of the nervous system, but it decreases apoptosis in the developing CNS and reduces neuronal death caused by Bcl-x disruption. ${ }^{50}$ Recent findings by Scorrano and coworkers ${ }^{51}$ suggest that Bax and another "multidomain" pro-apoptotic protein, Bak, are required to maintain homeostatic concentrations of $\mathrm{Ca}^{2+}$ in the endoplasmic reticulum (ER). The authors found that mouse embryonic fibroblasts deficient for both these proteins had a reduced resting concentration of calcium in the ER that results in decreased uptake of $\mathrm{Ca}^{2+}$ by mitochondria after $\mathrm{Ca}^{2+}$ release from the ER. Hence, this function of Bax and Bak may control the apoptotic fate of cells responding to $\mathrm{Ca}^{2+}$-dependent stimuli, such as oxidative stress.

Cytochrome $c$ release can be induced by members of the caspase family. ${ }^{52,53}$ Of particular interest are recent reports that suggest involvement of caspase- 2 in mitochondria-dependent apoptosis by inducing the release of cytochrome $c$ and other mitochondrial apoptogenic factors into the cell cytoplasm. ${ }^{53,54}$ However, other studies show that initiation of the intrinsic pathway is mediated before caspase activation. ${ }^{55}$

Apoptosome-mediated apoptosis may additionally be regulated by more complicated mechanisms. Thus, numerous alternatively spliced isoforms of certain apoptosis regulators, such as Bcl-x, ${ }^{56}$ caspase $-9,{ }^{57}$ and Apaf- $1^{58}$ have been shown to play opposing roles in regulating apoptosis. ${ }^{59}$ Furthermore, growth factors can promote cell survival by activating the phosphatidylinositide$3^{\prime}-\mathrm{OH}$ kinase and its downstream target, the serine-threonine kinase Akt. Cardone and collaborators ${ }^{60}$ found that active Akt can phosphorylate recombinant human caspase-9 on serine-196 and inhibit its activity. However, the corresponding Akt phosphorylation site was not found in the cloned mouse ortholog. ${ }^{61}$ Akt may inhibit activation of caspases- 9 and -3 by posttranslational modification of a cytosolic factor downstream of cytochrome $c$ and before activation of caspase- $9 .{ }^{62}$ Activation of the PI3'K/Akt signaling pathway by growth factors leads to phosphorylation of pro-apoptotic $\mathrm{Bad}^{63}$, thereby altering its function. On the other hand, an increase in intracellular $\mathrm{Ca}^{2+}$ concentration results in activation of the protein phosphatase calcineurin, which can dephosphorylate Bad. ${ }^{64}$ In other models, dephosphorylation of Bad can be achieved by Ras-dependent activation of the protein phosphatase $1 \alpha .{ }^{65}$ Dephosphorylated Bad forms a heterodimer with Bcl-xL, displacing Bax; this leads to the release of cytochrome $c$ and activation of downstream caspases, promoting apoptosis. ${ }^{66}$ Active caspase- 3 can specifically cleave Akt and, thus, amplify the death process. ${ }^{67}$

Other regulatory mechanisms that parallel the pro- 


\section{Mitochondrial Factors and Apoptosis}
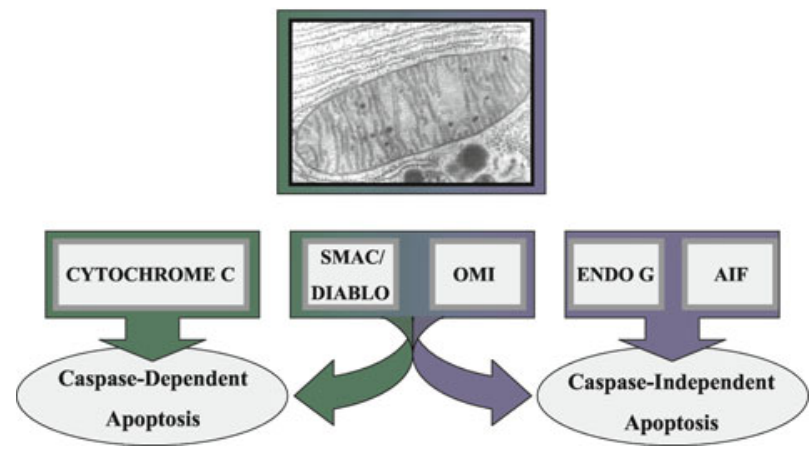

FIG. 2. A variety of mitochondrial proteins have been identified, whose translocation precipitates or contributes to apoptotic cell death. These include those leading primarily to caspase-dependent apoptosis (cytochrome $c$ ), to caspase-independent cell death (AIF, endonuclease G), or to both (Smac/DIABLO, Omi/ $\mathrm{HtrA})_{2}$.

apoptotic action of cytochrome $c$ involve the mitochondrial proteins Smac/DIABLO and Omi/HtrA2, which are also released into the cytosol when cells undergo apoptosis (FIG. 2). These proteins promote caspase-9 activation by modulating inhibitors of apoptosis proteins (IAPs), ${ }^{68}$ removing their inhibitory activity. ${ }^{69,70}$ Initially identified as baculoviral suppressors of apoptosis in host cells, seven IAP genes have been found in mammalian genomes. ${ }^{71}$ Anti-apoptotic activity of corresponding proteins has been attributed to the conserved baculovirus IAP repeat (BIR) domain. ${ }^{72}$ Members of this protein family, XIAP, c-IAP-1, and c-IAP-2 bind procaspase-9 and prevent its activation within the apoptosome and can also inhibit active caspases-3 and $-9 .{ }^{73}$

Smac seems to function as a general neutralizer of IAPs by binding to the BIR2 and BIR3 domains of c-IAP1, c-IAP2, and XIAP. ${ }^{69}$ This could presumably prevent interactions of the IAPs with caspases, therefore releasing their inhibition of caspase activation and caspase activities. ${ }^{69}$ The serine protease $\mathrm{Omi} / \mathrm{HtrA} 2$ is also released from mitochondria and inhibits the function of XIAP by direct binding in a way similar to Smac/ DIABLO. $^{74}$

Recently, Wang and co-workers ${ }^{75}$ identified two additional proteins that regulate mitochondrial cell death: the oncoprotein prothymosin- $\alpha$, which inhibits assembly of the apoptosome, and tumor suppressor putative HLADR-associated proteins (PHAPs), which stimulate activation of apoptosome. Previous studies have demonstrated that PHAPs can interact with the protein ataxin-1, suggesting that these proteins may contribute to a polyglutamine repeat disorder such as spinocerebellar ataxia type $\mathrm{I}^{76}$

The release of cytochrome $c$ from mitochondria to cytosol does not necessarily determine cell fate, since activation of the apoptosome is controlled by other factors. Thus, the cellular stress response can lead to cellular protection by inducing heat-shock proteins (Hsp). Two members of this family, Hsp70 and Hsp90, prevent cytochrome $c /$ dATP-mediated caspase activation by direct association with Apaf-1, thereby preventing recruitment of caspases to the apoptosome complex. ${ }^{77,78} \mathrm{~A}$ third member of the family, Hsp27, also inhibits cytochrome$c$-mediated activation of caspases by binding to cytochrome $c$ and thus prevents the interaction of Apaf-1 with procaspase- $9 .^{79}$

\section{Other caspases}

Nakagawa et al. ${ }^{80}$ showed that the caspase cascade can also be initiated by caspase-12. Caspase-12-knockout mice are resistant to apoptosis induced by cellular stress, and caspase-12-deficient cortical neurons are resistant to apoptosis induced by $\beta$-amyloid. In this stress-induced pathway caspase-12 activates caspase- 3 , and this process can be reversed by antisense-mediated inhibition of caspase-12. ${ }^{81}$ It has been proposed that increased intracellular $\mathrm{Ca}^{2+}$, resulting from ischemic injury or $\beta$-amyloid cytotoxicity, may induce apoptosis through simultaneous activation of caspase-12 and inactivation of Bcl-xL by calpain. ${ }^{82}$

Furthermore, in other models, an upstream activator of caspase- $1,{ }^{83}$ caspase- 11 is able to cleave and activate caspase-3. Caspase-11-deficient mice demonstrate reduced caspase- 3 activity and cell death caused by brain ischemia. ${ }^{84}$ This caspase has also been shown to be activated by cathepsin $\mathrm{B}^{85}$ that, in turn, can be activated by calpains. ${ }^{86}$

Results of several studies suggest that activation of caspase-2 plays a critical role in initiation and progression of apoptosis. Thus, diminished expression of this caspase in PC12 cells and sympathetic neurons mediated by antisense oligonucleotides rescues them from death caused by trophic factor deprivation. ${ }^{87}$ More recently, Lassus and collaborators ${ }^{53}$ demonstrated that caspase-2 is required for the permeabilization of mitochondria, the release of cytochrome $c$ and Smac, and translocation of Bax from the cytoplasm to mitochondria in response to cytotoxic stress.

In contrast, results of knockout studies show that death of motor neurons during development is accelerated in caspase-2-deficient mice, and that caspase-2-deficient sympathetic neurons undergo apoptosis more effectively than wild-type neurons when deprived of nerve growth factor. ${ }^{88}$ Thus, caspase- 2 may serve either as a positive or negative regulator of apoptosis.

\section{Developmental changes}

Clinical data suggest that outcomes and mortality after acute brain injury are age-dependent, with more severe responses in infants than in adults. ${ }^{89}$ Such differences in response to injury may be explained, in part, by differential susceptibility to apoptosis and associated caspase-3 activity in brain as a function of developmen- 
tal age..$^{90,92}$ During brain maturation, the potential of the intrinsic apoptotic pathway is progressively reduced; such repression is associated with down-regulation of Apaf- 1 and caspase- 3 gene expression. ${ }^{40}$ Injury-induced cytochrome $c$-specific cleavage of procaspase- 9 , followed by activation of caspase- 3 in mature brain, correlated with marked increases in Apaf-1 and caspase-3 mRNA and protein expression. ${ }^{40}$ These results suggest that differential expression of Apaf- 1 and caspase- 3 genes may underlie regulation of apoptotic susceptibility during brain development, as well as after acute injury to mature brain, through the intrinsic pathway of caspase activation.

\section{CASPASE-INDEPENDENT APOPTOSIS}

Although caspases have been recognized as important mediators of apoptosis, there is accumulating evidence suggesting the existence of caspase-independent mechanisms of neuronal death (FIG. 2) ${ }^{29,93}$ Blockade of the caspase execution machinery may only temporarily rescue damaged neurons, and classical apoptotic features can still appear in caspase-inhibited neurons and other cell types. ${ }^{94}$ In experimental models of stroke, caspase inhibition affords protection in certain neuronal populations but not in others. ${ }^{95}$ These results are consistent with the idea that the involvement of specific caspase-dependent and caspase-independent mechanisms of cell death may depend on brain region, cell type, and age. ${ }^{96} \mathrm{Al}-$ though there has been extensive investigation of caspasemediated cell death processes, much less is known about molecular mechanisms involved in the regulation of caspase-independent apoptosis and their role in brain development.

Specific mitochondrial factors appear to play a central role in both caspase-dependent and caspase-independent apoptosis. Thus, cytochrome $c$, Smac/DIABLO, and $\mathrm{HtrA} 2 / \mathrm{Omi}$ are released from mitochondria during initiation of apoptosis and control activation or activity of caspases. $^{29,69,74,93}$ In contrast, apoptosis-inducing factor (AIF) and endonuclease $\mathrm{G}$ promote caspase-independent cell death. ${ }^{29,93}$ However, Smac/DIABLO and HtrA2/Omi may also contribute to caspase-independent apoptosis. ${ }^{93}$

\section{AIF}

AIF normally localizes in mitochondria; however, after an apoptotic insult, it translocates to the cytosol and the nucleus, where it induces peripheral chromatin condensation and high molecular weight DNA fragmentation. ${ }^{93,97}$ Nuclear translocation of AIF has been observed under a wide variety of cell death inducing conditions such as protein kinase inhibition, c-Myc overexpression, ceramide exposure, or in vitro chemotherapy. ${ }^{93,97}$ Importantly, AIF translocation also occurs after ATP depletion that leads to inhibition of apoptosis and promotion of necrotic cell death. ${ }^{97}$ Intracellular redistribution of AIF correlates with large-scale DNA fragmentation and chromatin condensation, which occurs even in cells lacking Apaf-1 or caspase- $3 .^{98}$ This suggests that AIF may be responsible for the caspase-independent features of apoptosis. Kinetic analyses revealed that release of AIF from mitochondria does not correspond to that of cytochrome $c$ that has been explained by differential localization of these proteins within mitochondria. ${ }^{97}$

AIF possesses a second, oxidoreductase, enzymatic activity different from its apoptotic potential. ${ }^{99}$ The cellular targets of AIF remain elusive. However, heat shock protein 70 (Hsp70) physically interacts with AIF and inhibits its apoptotic effects both in vitro and in intact cells. ${ }^{100}$ Overexpression of $\mathrm{Bcl}-2$ also blocks the AIF redistribution. ${ }^{29}$

A recent study on Harlequin $(H q)$ mice has suggested a vital role for AIF in neuron survival in the aging mouse brain. ${ }^{101}$ In this report, Klein and co-authors ${ }^{101}$ found that $\mathrm{Hq}$ mutation caused an approximately $80 \%$ reduction in AIF expression and associated progressive degeneration of terminally differentiated cerebellar and retinal neurons in mice after 3 months of age. Reduced levels of AIF in mutant cells increased their susceptibility to exogenous and endogenous peroxide-mediated apoptosis that was inhibited by AIF overexpression. Furthermore, terminally differentiated neurons in the cerebellum and retina (but not in other neural tissues) undergo unscheduled cell cycle reentry, providing another molecular mechanism by which free-radical damage can lead to neuronal death. ${ }^{101}$ A pathway involving redistribution of AIF has been reported after acute brain injury in rats. ${ }^{102}$

In our preliminary studies, we demonstrated that in contrast to Apaf-1 and procaspase- 3 proteins, AIF is up-regulated during brain development in rats (Yakovlev, unpublished observation). This observation suggests that developmentally orchestrated regulation of Apaf-1, caspase-3, and AIF expression may determine the relative roles of caspase-dependent and caspase-independent mechanisms of neuronal cell loss in the course of brain maturation and brain injury.

\section{Endonuclease $\mathbf{G}$}

Endonuclease $\mathrm{G}$ was identified as the mitochondrial nuclease involved in mitochondrial DNA replication. ${ }^{103}$ It can be specifically activated by apoptotic stimuli, such as TNF- $\alpha$, anti-Fas antibodies, and UV irradiation, and, as for many other nucleases, induces internucleosomal fragmentation of nuclear DNA. ${ }^{104}$ Once released into the cytosol and translocated to the nucleus, this nuclease generates oligonucleosomal DNA fragmentation even in the presence of caspase inhibitors or absence of DNA fragmentation factor (DFF40), ${ }^{104}$ another apoptotic endonuclease that is activated by caspase- 3 and digests genomic DNA into oligonucleosomal fragments. ${ }^{2}$ DFF40 is a $40-\mathrm{kDa}$ protein that is translated in the pres- 
ence of its inhibitor (DFF45), which functions as a specific chaperone and forms a heterodimer with DFF40 in proliferating cells. Unlike endonuclease G, DFF45 is cleaved by caspase-3, releasing the nuclease activity of DFF40 from inhibitory control and triggering DNA fragmentation. ${ }^{105}$

In contrast to Li et al., ${ }^{104}$ who reported DNA laddering resulting from endonuclease $\mathrm{G}$ activity, Van Loo et al. ${ }^{106}$ only observed higher-order ( $\sim 50 \mathrm{~kb})$ DNA degradation. Furthermore, in comparison to DFF40, much higher concentrations of endonuclease $G$ are required for DNA degradation, ${ }^{93}$ suggesting a requirement for other cofactors, such as DNase $\mathrm{I},{ }^{107}$ to induce effective DNA fragmentation.

\section{Omi/HtrA2}

Protein analysis of supernatants isolated from mitochondria exposed to recombinant tBid, a pro-apoptotic $\mathrm{Bcl}-2$ member, revealed the presence of the serine protease Omi, also called HtrA2 ${ }^{70}$ The autoprocessed amino-terminal domain of HtrA2/Omi demonstrates homology to Smac/DIABLO and Reaper family proteins. ${ }^{29}$ Processed Omi/HtrA2 is released to the cytoplasm upon induction of apoptosis where it binds XIAP resulting in caspase-9 activation. ${ }^{29,70,93}$ This function of Omi is similar to that of Smac/DIABLO, which also binds IAPs and activates caspase- $9^{108}$; however, HtrA2/Omi can also induce apoptosis in a caspase-independent manner. ${ }^{29,93}$ When overexpressed extramitochondrially, it induces cell death, which is neither accompanied by significant caspase activation nor prevented by caspase inhibitors. This effect of HtrA2/Omi appears to depend on its serine protease activity, since its catalytically inactive mutant does not induce cell death. ${ }^{70,74}$

\section{Smac/DIABLO}

Smac/DIABLO is also able to induce cell death independently of its binding to IAPs. Thus, Roberts and coworkers ${ }^{109}$ have demonstrated that a short splice variant of Smac/DIABLO (Smac $\beta$ ) that lacks the mitochondria targeting and IAPs binding domains potentiates apoptosis induced by death receptor and chemical stimuli. Furthermore, expression of a NH(2)-terminally truncated Smac mutant (Delta75), which lacks the entire IAP-interacting domain, potentiates apoptosis to the same extent as Smac/DIABLO and Smac $\beta{ }^{109}$

Although expression of Smac/DIABLO is undetectable in adult mouse brain under normal conditions, Shibata and collaborators ${ }^{110}$ reported its induction after transient focal ischemia in mice. However, it is still unclear whether this mitochondrial protein plays an essential role in neuronal death in vivo, since the knockout mice are viable and do not demonstrate any obvious phenotypic abnormality; moreover, Smac/DIABLO ${ }^{-/-}$cells undergo typical apoptosis induced by a variety of stimuli. ${ }^{111}$

\section{MOLECULAR PATHWAYS OF CELL NECROSIS}

Neuronal necrosis is often observed under severe pathophysiological conditions, such as hypoxia, ischemia, hypoglycemia, exposure to reactive oxygen metabolites and toxins, among others. This type of cell death has also been described in such neurodegenerative disorders as Alzheimer's, Huntington's, Parkinson's diseases, amyotrophic lateral sclerosis, and epilepsy. ${ }^{112,113}$ Moreover, autophagic and cytoplasmic types represent alternative necrosis-like forms of programmed cell death that normally occur during development. ${ }^{114}$

In contrast to apoptosis, necrosis has been considered a passive and disordered process leading to accidental and unavoidable death of cells exposed to extreme insults. However, new findings have revised this concept. Thus, execution of necrotic death depends on activation of $\mathrm{Ca}^{2+}$-dependent proteolysis that employs proteases different from caspases. Moreover, similar morphological and ultrastructural features of necrotic cells of different origin suggests existence of a conserved execution program. Recent studies on genetic mechanisms of excitotoxic degeneration of the six touch receptor neurons in C. elegans established a role for CLP-1 and TRA-3 calpain-like proteases and aspartyl proteases ASP-3 and ASP-4, two orthologs of mammalian cathepsins. ${ }^{115}$ The authors demonstrated that overexpression of ASP-3 and -4 can induce spontaneous vacuolization and death of neurons in the ventral nerve cord. RNAi-mediated inhibition of ASP-3 and -4 expression resulted in neuroprotection.

According to the "calpain-cathepsin" hypothesis, activation of cathepsins occurs as a result of $\mathrm{Ca}^{2+}$-dependent activation of calpains. In agreement with this hypothesis, inhibition of calpain activity in worms by $\mathrm{z}$-Val-Phe-CHO markedly reduced the number of degenerating neurons. RNAi-mediated knockdown of six of 17 C. elegans calpain homologs revealed an essential role for $c l p-1$ and tra-3 genes in neuronal loss. Simultaneous repression of both calpain or both cathepsin genes by RNAi resulted in an enhanced suppression of neurodegeration. However, no synergy was observed between aspartyl proteases and calpain, suggesting their contribution to the same pathway of neurodegeneration in $C$. elegans. Overall, results of this study indicate that diverse death-initiating conditions lead to $\mathrm{Ca}^{2+}$-dependent activation of calpains and a subsequent increase in cathepsins activity, leading to cell destruction. ${ }^{15}$

\section{Calpains}

Mammalian calpains compose a large family of constitutively expressed intracellular cysteine proteases. ${ }^{86}$ Two major groups of these enzymes are known as $\mu$-and m-calpains (also called calpains I and II, respectively). The enzymes of both groups require $\mathrm{Ca}^{2+}$ for their ac- 
tivation. While $\mu$-calpains are active at micromolar $\mathrm{Ca}^{2+}$ concentrations in vitro, active m-calpains require millimolar $\mathrm{Ca}^{2+}$. Although a large number of calpain substrates have been demonstrated, including cytoskeletal proteins, growth factor receptors, and transcription- and cell-cycle-related proteins, the precise function of calpains in vivo remains unclear. ${ }^{86}$

Calpains have been proposed to play a role in regulating normal signal transduction processes by cleaving cytoskeletal proteins such as talin and $\alpha$-actinin, membrane proteins such as the epidermal growth factor receptor, integrin, N-CAM, and cadherin, and enzymes such as protein kinase $\mathrm{C}$ and calmodulin-dependent kinase. ${ }^{116}$ Constitutive expression of calpains in mammalian CNS and the property of activation by $\mathrm{Ca}^{2+}$ indicate that these proteases can also contribute to neurodegeneration. Activation of calpains has been proposed to contribute to neuronal cell death in ischemic brain injury, ${ }^{117}$ brain trauma, ${ }^{118}$ and Alzheimer's disease. ${ }^{119}$ Moreover, calpain inhibitors show neuroprotective effects in animal models of cerebral ischemia ${ }^{117}$ and traumatic brain injury. ${ }^{118}$

\section{Cathepsins}

Like calpains, cathepsins also belong to the papain superfamily of cysteine proteases. They are synthesized as inactive precursors and undergo proteolytic activation. Cathepsins are localized predominantly to the lysosomes, but have also been found in cell nuclei and cytosol. ${ }^{86}$ Neuronal lysosomes are known to contain at least cathepsins B, D, and L; activity of these enzymes has been implicated neuronal injury, ${ }^{86}$ and cathepsin inhibitors such as CA-074 and E-64c have been demonstrated to significantly inhibit neuronal death. ${ }^{120}$

The cytosolic activity of cathepsin D increases significantly from 2 to 6 months in the rat brain, and by 36 months it shows twice the activity of the lysosomal/ mitochondrial fraction. ${ }^{121}$ Our preliminary data, on the other hand, suggest that in contrast to the pro-apoptotic genes, such as procaspase- 3 and Apaf-1, m-calpain protein expression is up-regulated during rat brain development (unpublished observations). Taken together, regulatory mechanisms that control expression of key apoptotic and necrotic genes during brain development appear to predetermine different types of injury-induced neuronal death.

\section{COOPERATION OF CELL DEATH PROGRAMS}

As indicated previously, morphological descriptions of apoptosis and necrosis do not describe all variations of cell death. There are many examples when biochemical and morphological features of more than one type of programmed death can be found in the same cell, ${ }^{113}$ and inhibition of one form of cell death can lead to domina- tion of another. ${ }^{7}$ These experimental studies support the existence of a spectrum of death programs in cells. ${ }^{21}$ Thus, Formigli and collaborators ${ }^{21}$ found that antimycin A, a metabolic poison that affects mitochondrial respiratory chain complex III, induced a type of cell death that shared dynamic, molecular, and morphological features with both apoptosis and necrosis, which they called aponecrosis. Inhibition of caspase-3 caused a shift from aponecrosis to necrosis, and higher doses of antimycin A induced necrosis. The analysis of the cellular energetic stores showed that the levels of ATP were a primary determinant in directing toward active cell death (apoptosis), aponecrosis, or necrosis. These and other recent data indicate that apoptosis and necrosis may not necessarily be two independent pathways, but rather may share some common events, at least with regard to signal transduction pathways and early phases of the cell death process. This idea is consistent with observations that anti-apoptotic genes, such as $b c l-2$, are able to inhibit both apoptotic and necrotic cell death. ${ }^{122}$

Furthermore, it is becoming increasingly clear that various types of cell death can share pathways of their execution. For example, recent data suggest a cross-talk between calpains and caspases. Thus, m-calpain can cleave and activate procaspase-12, leading to the caspase cascade. ${ }^{82}$ In addition, calpain may be responsible for cleaving the loop region in Bcl-xL, thereby transforming an anti-apoptotic molecule into a pro-apoptotic one. ${ }^{82}$

\section{CELL DEATH MECHANISMS: IMPLICATIONS FOR TREATMENT}

The existence of multiple cell death pathways with both overlapping and distinct molecular mechanisms, combined with the observation that inhibition of one such pathway may enhance alternative ones, suggest that treatment strategies should optimally be directed at multiple targets/mechanisms. Traditionally, neuroprotection treatment approaches have focused on single receptors or injury factors, and have been primarily aimed at reducing necrotic cell death. ${ }^{11}$ Because necrosis is an early event, and it is often not possible to treat patients until many hours after acute injuries, such strategies are not likely to be effective. Indeed, virtually all neuroprotective treatment trials in stroke or traumatic brain injury have failed. ${ }^{11,123}$ Alternatively, many recent experimental studies have attempted to modulate caspase-mediated apoptosis. Such studies may make more conceptual sense, as apoptosis is a more delayed event, and use of caspase inhibitors has proved effective in experimental stroke, head injury, and spinal cord injury. ${ }^{35}$ However, this approach is potentially problematic for several reasons. First, there is evidence that inhibition of apoptosis may enhance necrotic cell death. ${ }^{21}$ Second, the effectiveness of peptide caspase inhibitors may relate to their ability to reduce necrotic cell 
death, possibly mediated by calpains (Knoblach and Faden, unpublished observations).

These observations suggest that optimal neuroprotective approaches should include either combination treatment strategies directed toward multiple cell death pathways or the use of single compounds that may inhibit more than one cell death mechanism (multipotential agents). We have previously shown in a cell culture model of traumatic neuronal cell death, which induces both apoptotic and necrotic cell death, that combination treatment with an NMDA antagonist and a caspase inhibitor has additive, if not synergistic, neuroprotective actions. $^{124}$

A prototypic multipotential agent is thyrotropin-releasing hormone (TRH). TRH serves as a physiologic antagonist for endogenous opioids, peptidyl leukotrienes, and platelet-activating factor, all of which have been implicated in secondary tissue injury; it also improves cerebral blood flow, cellular bioenergetic state, and ionic homeostasis. ${ }^{125}$ TRH has substantial neuroprotective actions in brain and spinal cord injury models, ${ }^{126}$ and has shown effectiveness in human spinal cord injury. ${ }^{9}$

During the past several years, a number of other neuroprotective agents have been evaluated that have multipotential actions. Dexanabinol (HU-211) is an NMDA antagonist that also has antioxidant and anti-TNF properties; it has good neuroprotective activity in experimental models of stroke and head injury. ${ }^{127}$ AM36 has actions as a sodium channel blocker, NMDA antagonist and free radical scavenger. ${ }^{128}$ It has been shown to have neuroprotective actions in vivo and in vitro, as well as anti-apoptotic effects. ${ }^{128,129} 35 \mathrm{~b}$ is a cyclized dipeptide, somewhat related to a metabolic product of TRH, which blocks both apoptotic (caspase-dependent) and necrotic cell death in primary neuronal cell cultures, and shows striking neuroprotective actions following traumatic brain injury in rats and mice. ${ }^{130,131}$

As molecular mechanisms of non-caspase-dependent programmed cell death are defined, other types of combined treatment or multipotential treatment approaches should be developed. Because multiple cell death pathways may have common upstream initiators, or share signal transduction cascades, new drug development strategies directed at such common targets should be considered for the treatment of both acute and chronic neurodegenerative disorders.

Acknowledgments: This work was supported by Department of Defense Cooperative Agreement DAMD17-99-29007, NIH Grants R01 NS36537 and R01 NS41119 to A. I. F., NIH Grant P30 HD40677 Core Subcontract to A. I. F., and NIH Grant R01 NS38941 to A.G.Y.

\section{REFERENCES}

1. Eldadah BA, Faden AI. Caspase pathways, neuronal apoptosis, and CNS injury. J Neurotrauma 17:811-829, 2000.
2. Snider BJ, Gottron FJ, Choi DW. Apoptosis and necrosis in cerebrovascular disease. Ann NY Acad Sci 893:243-253, 1999.

3. Graeber MB, Moran LB. Mechanisms of cell death in neurodegenerative diseases: fashion, fiction, and facts. Brain Pathol 12: 385-390, 2002.

4. Honig LS, Rosenberg RN. Apoptosis and neurologic disease. Am J Med 108:317-330, 2000.

5. Panter SS, Faden AI. Biochemical changes and secondary injury from stroke and trauma. In: Principles and practice of restorative neurology, Chap 5 (Young RR, Delwade PJ, eds), pp 32-52. New York: Butterworth's, 1992.

6. McIntosh TK. Neurochemical sequelae of traumatic brain injury: therapeutic implications. Cerebrovasc Brain Metab Rev 6:109162, 1994.

7. Pohl D, Bittigau P, Ishimaru MJ, Stadthaus D, Hubner C, Olney JW et al. N-methyl-D-aspartate antagonists and apoptotic cell death triggered by head trauma in developing rat brain. Proc Natl Acad Sci USA 96:2508-2513, 1999.

8. Faden AI. Pharmacological treatment of central nervous system trauma. Pharmacol Toxicol 78:12-17, 1996.

9. Pitts LH, Ross A, Chase GA, Faden AI. Treatment with thyrotropin-releasing hormone (TRH) in patients with traumatic spinal cord injuries. J Neurotrauma 12:235-243, 1995.

10. Bracken MB, Holford TR. Effects of timing of methylprednisolone or naloxone administration on recovery of segmental and long-tract neurological function in NASCIS 2. J Neurosurg 79: 500-507, 1993.

11. Faden AI. Neuroprotection and traumatic brain injury: theoretical option or realistic proposition. Curr Opin Neurol 15:707-712, 2002.

12. Lees KR. Neuroprotection is unlikely to be effective in humans using current trial designs: an opposing view. Stroke 33:308-309, 2002.

13. Schweichel JU, Merker HJ. The morphology of various types of cell death in prenatal tissues. Teratology 7:253-266, 1973.

14. Kerr JF, Wyllie AH, Currie AR. Apoptosis: A basic biological phenomenon with wide-ranging implications in tissue kinetics. Br J Cancer 26:239-257, 1972.

15. Kitanaka C, Kuchino Y. Caspase-independent programmed cell death with necrotic morphology. Cell Death Differ 6:508-515, 1999.

16. Clarke PG. Developmental cell death: morphological diversity and multiple mechanisms. Anat Embryol (Berl) 181:195-213, 1990.

17. Van Cruchten S, Van Den Broeck W. Morphological and biochemical aspects of apoptosis, oncosis and necrosis. Anat Histol Embryol 31:214-223, 2002.

18. Bursch W. The autophagosomal-lysosomal compartment in programmed cell death. Cell Death Differ 8:569-581, 2001.

19. Bredesen DE. Neural apoptosis. Ann Neurol 38:839-851, 1995

20. Levin S, Bucci TJ, Cohen SM, Fix AS, Hardisty JF, LeGrand EK et al. The nomenclature of cell death: recommendations of an $a d$ hoc Committee of the Society of Toxicologic Pathologists. Toxicol Pathol 27:484-490, 1999.

21. Formigli L, Papucci L, Tani A, Schiavone N, Tempestini A, Orlandini GE et al. Aponecrosis: morphological and biochemical exploration of a syncretic process of cell death sharing apoptosis and necrosis. J Cell Physiol 182:41-49, 2000.

22. Bonfoco E, Krainc D, Ankarcrona M, Nicotera P, Lipton SA. Apoptosis and necrosis: two distinct events induced, respectively, by mild and intense insults with N-methyl-D-aspartate or nitric oxide/superoxide in cortical cell cultures. Proc Natl Acad Sci USA 92:7162-7166, 1995.

23. Eguchi Y, Shimizu S, Tsujimoto Y. Intracellular ATP levels determine cell death fate by apoptosis or necrosis. Cancer Res 57:1835-1840, 1997.

24. Turmaine M, Raza A, Mahal A, Mangiarini L, Bates GP, Davies SW. Nonapoptotic neurodegeneration in a transgenic mouse model of Huntington's disease. Proc Natl Acad Sci USA 97: 8093-8097, 2000.

25. Fiskum G. Mitochondrial participation in ischemic and traumatic neural cell death. $J$ Neurotrauma 17:843-855, 2000. 
26. Dal Canto MC, Gurney ME. Development of central nervous system pathology in a murine transgenic model of human amyotrophic lateral sclerosis. Am J Pathol 145:1271-1279, 1994.

27. Sperandio S, de Belle I, Bredesen DE. An alternative, nonapoptotic form of programmed cell death. Proc Natl Acad Sci USA 97:14376-14381, 2000.

28. Castro-Obregon S, Del Rio G, Chen SF, Swanson RA, Frankowski H, Rao RV et al. A ligand-receptor pair that triggers a non-apoptotic form of programmed cell death. Cell Death Differ 9:807-817, 2002.

29. Ravagnan L, Roumier T, Kroemer G. Mitochondria, the killer organelles and their weapons. J Cell Physiol 192:131-137, 2002.

30. Hengartner MO. Programmed cell death in the nematode C. elegans. Recent Prog Horm Res 54:213-222, 1999.

31. Alnemri ES, Livingston DJ, Nicholson DW, Salvesen G, Thornberry NA, Wong WW et al. Human ICE/ced-3 protease nomenclature [letter]. Cell 87:171, 1996.

32. Ethell DW, Bossy-Wetzel E, Bredesen DE. Caspase 7 can cleave tumor necrosis factor receptor-I (p60) at a non-consensus motif, in vitro. Biochim Biophys Acta 1541:231-238, 2001.

33. Cohen GM. Caspases: the executioners of apoptosis. Biochem $J$ 326:1-16, 1997.

34. Kuida K, Zheng TS, Na S, Kuan C, Yang D, Karasuyama H et al. Decreased apoptosis in the brain and premature lethality in CPP32- deficient mice. Nature 384:368-372, 1996.

35. Yakovlev AG, Faden AI. Caspase-dependent apoptotic pathways in CNS injury. Mol Neurobiol 24:131-144, 2001.

36. Aravind L, Dixit VM, Koonin EV. The domains of death: evolution of the apoptosis machinery. Trends Biochem Sci 24:47-53, 1999.

37. Slee EA, Harte MT, Kluck RM, Wolf BB, Casiano CA, Newmeyer DD et al. Ordering the cytochrome c-initiated caspase cascade: hierarchical activation of caspases-2, -3, -6, -7, -8, and -10 in a caspase-9-dependent manner. J Cell Biol 144:281-292, 1999.

38. Luo X, Budihardjo I, Zou H, Slaughter C, Wang X. Bid, a Bcl2 interacting protein, mediates cytochrome c release from mitochondria in response to activation of cell surface death receptors. Cell 94:481-490, 1998.

39. Cory S, Adams JM. The Bcl2 family: Regulators of the cellular life-or-death switch. Nat Rev Cancer 2:647-656, 2002.

40. Yakovlev AG, Ota K, Wang G, Movsesyan V, Bao WL, Yoshihara $\mathrm{K}$ et al. Differential expression of apoptotic protease-activating factor- 1 and caspase- 3 genes and susceptibility to apoptosis during brain development and after traumatic brain injury. $J$ Neurosci 21:7439-7446, 2001.

41. Kuida K, Haydar TF, Kuan CY, Gu Y, Taya C, Karasuyama H et al. Reduced apoptosis and cytochrome c-mediated caspase activation in mice lacking caspase 9. Cell 94:325-337, 1998.

42. Gonzalez-Garcia M, Perez-Ballestero R, Ding L, Duan L, Boise $\mathrm{LH}$, Thompson CB et al. Bcl-XL is the major Bcl-x mRNA form expressed during murine development and its product localizes to mitochondria. Development 120:3033-3042, 1994.

43. Motoyama N, Wang F, Roth KA, Sawa H, Nakayama K, Negishi I et al. Massive cell death of immature hematopoietic cells and neurons in Bcl-x-deficient mice. Science 267:1506-1510, 1995.

44. Moriishi K, Huang DC, Cory S, Adams JM. Bcl-2 family members do not inhibit apoptosis by binding the caspase activator Apaf-1. Proc Natl Acad Sci USA 96:9683-9688, 1999.

45. Hausmann G, O'Reilly LA, van Driel R, Beaumont JG, Strasser A, Adams JM et al. Pro-apoptotic apoptosis protease-activating factor 1 (Apaf-1) has a cytoplasmic localization distinct from Bcl-2 or Bcl-x(L). J Cell Biol 149:623-634, 2000.

46. Shimizu S, Konishi A, Kodama T, Tsujimoto Y. Bh4 domain of antiapoptotic Bcl-2 family members closes voltage-dependent anion channel and inhibits apoptotic mitochondrial changes and cell death [Erratum 1;97:9347, 2000]. Proc Natl Acad Sci USA 97: 3100-3105, 2000.

47. Fujita N, Nagahashi A, Nagashima K, Rokudai S, Tsuruo T. Acceleration of apoptotic cell death after the cleavage of Bcl-XL protein by caspase-3-like proteases. Oncogene 17:1295-1304, 1998.

48. Hsu YT, Wolter KG, Youle RJ. Cytosol-to-membrane redistribu- tion of Bax and Bcl-X(L) during apoptosis. Proc Natl Acad Sci USA 94:3668-3672, 1997.

49. Gross A, Jockel J, Wei MC, Korsmeyer SJ. Enforced dimerization of Bax results in its translocation, mitochondrial dysfunction and apoptosis. EMBO J 17:3878-3885, 1998.

50. Shindler KS, Latham CB, Roth KA. Bax deficiency prevents the increased cell death of immature neurons in bcl-X-deficient mice. J Neurosci 17:3112-3119, 1997.

51. Scorrano L, Oakes SA, Opferman JT, Cheng EH, Sorcinelli MD, Pozzan T et al. Bax and Bak regulation of endoplasmic reticulum CA2 + : a control point for apoptosis. Science 300:135-139, 2003.

52. Bossy-Wetzel E, Green DR. Caspases induce cytochrome c release from mitochondria by activating cytosolic factors. $J$ Biol Chem 274:17484-17490, 1999.

53. Lassus P, Opitz-Araya X, Lazebnik Y. Requirement for caspase-2 in stress-induced apoptosis before mitochondrial permeabilization. Science 297:1352-1354, 2002.

54. Guo Y, Srinivasula SM, Druilhe A, Fernandes-Alnemri T, Alnemri ES. Caspase-2 induces apoptosis by releasing proapoptotic proteins from mitochondria. J Biol Chem 277:13430-13437, 2002.

55. Schuler M, Bossy-Wetzel E, Goldstein JC, Fitzgerald P, Green DR. P53 induces apoptosis by caspase activation through mitochondrial cytochrome c release. J Biol Chem 275:7337-7342, 2000.

56. Minn AJ, Boise LH, Thompson CB. Bcl-x(S) antagonizes the protective effects of Bcl-x(L). J Biol Chem 271:6306-6312, 1996.

57. Srinivasula SM, Ahmad M, Guo Y, Zhan Y, Lazebnik Y, Fernandes-Alnemri $\mathrm{T}$ et al. Identification of an endogenous dominant-negative short isoform of caspase-9 that can regulate apoptosis. Cancer Res 59:999-1002, 1999.

58. Benedict MA, Hu Y, Inohara N, Nunez G. Expression and functional analysis of Apaf-1 isoforms. Extra Wd-40 repeat is required for cytochrome $\mathrm{c}$ binding and regulated activation of procaspase-9. J Biol Chem 275:8461-8468, 2000.

59. Jiang $\mathrm{ZH}, \mathrm{Wu}$ JY. Alternative splicing and programmed cell death. Proc Soc Exp Biol Med 220:64-72, 1999.

60. Cardone MH, Roy N, Stennicke HR, Salvesen GS, Franke TF, Stanbridge E et al. Regulation of cell death protease caspase- 9 by phosphorylation. Science 282:1318-1321, 1998.

61. Fujita E, Jinbo A, Matuzaki H, Konishi H, Kikkawa U, Momoi T. Akt phosphorylation site found in human caspase- 9 is absent in mouse caspase-9. Biochem Biophys Res Commun 264:550-555, 1999.

62. Zhou H, Li XM, Meinkoth J, Pittman RN. Akt regulates cell survival and apoptosis at a postmitochondrial level. J Cell Biol 151:483-494, 2000.

63. Datta SR, Dudek H, Tao X, Masters S, Fu H, Gotoh Y et al. Akt phosphorylation of BAD couples survival signals to the cellintrinsic death machinery. Cell 91:231-241, 1997.

64. Wang HG, Pathan N, Ethell IM, Krajewski S, Yamaguchi Y, Shibasaki $\mathrm{F}$ et al. $\mathrm{Ca} 2+$-induced apoptosis through calcineurin dephosphorylation of BAD. Science 284:339-343, 1999.

65. Ayllon V, Martinez AC, Garcia A, Cayla X, Rebollo A. Protein phosphatase $1 \alpha$ is a Ras-activated Bad phosphatase that regulates interleukin-2 deprivation-induced apoptosis. EMBO J 19:22372246, 2000.

66. Yang E, Zha J, Jockel J, Boise LH, Thompson CB, Korsmeyer SJ. $\mathrm{Bad}$, a heterodimeric partner for Bcl-XL and Bcl-2, displaces Bax and promotes cell death. Cell 80:285-291, 1995.

67. Francois F, Grimes ML. Phosphorylation-dependent Akt cleavage in neural cell in vitro reconstitution of apoptosis. J Neurochem 73:1773-1776, 1999.

68. Hay BA. Understanding IAP function and regulation: a view from drosophila. Cell Death Differ 7:1045-1056, 2000.

69. Du C, Fang M, Li Y, Li L, Wang X. Smac, a mitochondrial protein that promotes cytochrome c-dependent caspase activation by eliminating IAP inhibition. Cell 102:33-42, 2000.

70. Hegde R, Srinivasula SM, Zhang Z, Wassell R, Mukattash R, Cilenti L et al. Identification of Omi/HtrA2 as a mitochondrial apoptotic serine protease that disrupts inhibitor of apoptosis protein-caspase interaction. J Biol Chem 277:432-438, 2002. 
71. Deveraux QL, Reed JC. IAP family proteins-suppressors of apoptosis. Genes Dev 13:239-252, 1999.

72. Takahashi R, Deveraux Q, Tamm I, Welsh K, Assa-Munt N, Salvesen GS et al. A single BIR domain of XIAP sufficient for inhibiting caspases. J Biol Chem 273:7787-7790, 1998.

73. Deveraux QL, Roy N, Stennicke HR, Van Arsdale T, Zhou Q, Srinivasula SM et al. IAPs block apoptotic events induced by caspase- 8 and cytochrome $\mathrm{c}$ by direct inhibition of distinct caspases. EMBO J 17:2215-2223, 1998.

74. Suzuki Y, Imai Y, Nakayama H, Takahashi K, Takio K, Takahashi R. A serine protease, HtrA2, is released from the mitochondria and interacts with XIAP, inducing cell death. Mol Cell 8:613-621, 2001.

75. Jiang X, Kim HE, Shu H, Zhao Y, Zhang H, Kofron J et al. Distinctive roles of PHAP proteins and prothymosin-alpha in a death regulatory pathway. Science 299:223-226, 2003.

76. Matilla A, Koshy BT, Cummings CJ, Isobe T, Orr HT, Zoghbi HY. The cerebellar leucine-rich acidic nuclear protein interacts with ataxin-1. Nature 389:974-978, 1997.

77. Pandey P, Saleh A, Nakazawa A, Kumar S, Srinivasula SM, Kumar $\mathrm{V}$ et al. Negative regulation of cytochrome c-mediated oligomerization of Apaf- 1 and activation of procaspase- 9 by heat shock protein 90. EMBO J 19:4310-4322, 2000.

78. Beere HM, Wolf BB, Cain K, Mosser DD, Mahboubi A, Kuwana $\mathrm{T}$ et al. Heat-shock protein 70 inhibits apoptosis by preventing recruitment of procaspase-9 to the Apaf-1 apoptosome. Nat Cell Biol 2:469-475, 2000.

79. Bruey JM, Ducasse C, Bonniaud P, Ravagnan L, Susin SA, Diaz-Latoud $\mathrm{C}$ et al. Hsp27 negatively regulates cell death by interacting with cytochrome c. Nat Cell Biol 2:645-652, 2000.

80. Nakagawa T, Zhu H, Morishima N, Li E, Xu J, Yankner BA et al. Caspase-12 mediates endoplasmic-reticulum-specific apoptosis and cytotoxicity by amyloid-beta. Nature 403:98-103, 2000.

81. Bitko V, Barik S. An endoplasmic reticulum-specific stress-activated caspase (caspase-12) is implicated in the apoptosis of A549 epithelial cells by respiratory syncytial virus. J Cell Biochem 80:441-454, 2001.

82. Nakagawa T, Yuan J. Cross-talk between two cysteine protease families. Activation of caspase-12 by calpain in apoptosis. $J$ Cell Biol 150:887-894, 2000.

83. Wang S, Miura M, Jung YK, Zhu H, Li E, Yuan J. Murine caspase-11, an ICE-interacting protease, is essential for the activation of ICE. Cell 92:501-509, 1998.

84. Kang SJ, Wang S, Hara H, Peterson EP, Namura S, AminHanjani $S$ et al. Dual role of caspase-11 in mediating activation of caspase-1 and caspase-3 under pathological conditions. J Cell Biol 149:613-622, 2000.

85. Schotte P, Van Criekinge W, Van de Craen M, Van Loo G, Desmedt M, Grooten J et al. Cathepsin B-mediated activation of the proinflammatory caspase- 11 . Biochem Biophys Res Commun 251:379-387, 1998.

86. Yamashima T. Implication of cysteine proteases calpain, cathepsin and caspase in ischemic neuronal death of primates. Prog Neurobiol 62:273-295, 2000.

87. Troy CM, Stefanis L, Greene LA, Shelanski ML. Nedd2 is required for apoptosis after trophic factor withdrawal, but not superoxide dismutase (SOD1) downregulation, in sympathetic neurons and PC12 cells. J Neurosci 17:1911-1918, 1997.

88. Bergeron L, Perez GI, Macdonald G, Shi L, Sun Y, Jurisicova A et al. Defects in regulation of apoptosis in caspase-2-deficient mice. Genes Dev 12:1304-1314, 1998.

89. Adelson PD, Kochanek PM. Head injury in children. $J$ Child Neurol 13:2-15, 1998.

90. de Bilbao F, Guarin E, Nef P, Vallet P, Giannakopoulos P, Dubois-Dauphin M. Postnatal distribution of cpp32/caspase 3 mRNA in the mouse central nervous system: an in situ hybridization study. J Comp Neurol 409:339-357, 1999.

91. Bittigau P, Sifringer M, Pohl D, Stadthaus D, Ishimaru M, Shimizu $\mathrm{H}$ et al. Apoptotic neurodegeneration following trauma is markedly enhanced in the immature brain. Ann Neurol 45:724$735,1999$.

92. Hu BR, Liu CL, Ouyang Y, Blomgren K, Siesjo BK. Involvement of caspase-3 in cell death after hypoxia-ischemia declines during brain maturation. J Cereb Blood Flow Metab 20:1294-1300, 2000.

93. van Loo G, Saelens X, van Gurp M, MacFarlane M, Martin SJ, Vandenabeele P. The role of mitochondrial factors in apoptosis: a Russian roulette with more than one bullet. Cell Death Differ 9:1031-1042, 2002.

94. Volbracht C, Leist M, Kolb SA, Nicotera P. Apoptosis in caspaseinhibited neurons. Mol Med 7:36-48, 2001.

95. Zhan RZ, Wu C, Fujihara H, Taga K, Qi S, Naito M et al. Both caspase-dependent and caspase-independent pathways may be involved in hippocampal CA1 neuronal death because of loss of cytochrome $\mathrm{c}$ from mitochondria in a rat forebrain ischemia model. J Cereb Blood Flow Metab 21:529-540, 2001.

96. Oppenheim RW, Flavell RA, Vinsant S, Prevette D, Kuan CY, Rakic P. Programmed cell death of developing mammalian neurons after genetic deletion of caspases. $J$ Neurosci 21:4752-4760, 2001.

97. Daugas E, Susin SA, Zamzami N, Ferri KF, Irinopoulou T, Larochette $\mathrm{N}$ et al. Mitochondrio-nuclear translocation of AIF in apoptosis and necrosis. FASEB $J$ 14:729-739, 2000.

98. Loeffler M, Daugas E, Susin SA, Zamzami N, Metivier D, Nieminen $\mathrm{AL}$ et al. Dominant cell death induction by extramitochondrially targeted apoptosis-inducing factor. FASEB $J$ 15:758 767, 2001.

99. Susin SA, Lorenzo HK, Zamzami N, Marzo I, Snow BE, Brothers GM et al. Molecular characterization of mitochondrial apoptosisinducing factor. Nature 397:441-446, 1999.

100. Ravagnan L, Gurbuxani S, Susin SA, Maisse C, Daugas E, Zamzami $\mathrm{N}$ et al. Heat-shock protein 70 antagonizes apoptosisinducing factor. Nat Cell Biol 3:839-843, 2001.

101. Klein JA, Longo-Guess CM, Rossmann MP, Seburn KL, Hurd RE, Frankel WN et al. The harlequin mouse mutation downregulates apoptosis-inducing factor. Nature 419:367-374, 2002.

102. Zhang X, Chen J, Graham SH, Du L, Kochanek PM, Draviam R et al. Intranuclear localization of apoptosis-inducing factor (AIF) and large scale DNA fragmentation after traumatic brain injury in rats and in neuronal cultures exposed to peroxynitrite. J Neurochem 82:181-191, 2002.

103. Cote J, Ruiz-Carrillo A. Primers for mitochondrial DNA replication generated by endonuclease G. Science 261:765-769, 1993.

104. Li LY, Luo X, Wang X. Endonuclease G is an apoptotic DNase when released from mitochondria. Nature 412:95-99, 2001.

105. Liu X, Zou H, Slaughter C, Wang X. DFF, a heterodimeric protein that functions downstream of caspase-3 to trigger DNA fragmentation during apoptosis. Cell 89:175-184, 1997.

106. van Loo G, Schotte P, van Gurp M, Demol H, Hoorelbeke B, Gevaert $\mathrm{K}$ et al. Endonuclease G: a mitochondrial protein released in apoptosis and involved in caspase-independent DNA degradation. Cell Death Differ 8:1136-1142, 2001.

107. Widlak P, Li LY, Wang X, Garrard WT. Action of recombinant human apoptotic endonuclease G on naked DNA and chromatin substrates: cooperation with exonuclease and DNase I. J Biol Chem 276:48404-48409, 2001.

108. Srinivasula SM, Datta P, Fan XJ, Fernandes-Alnemri T, Huang Z, Alnemri ES. Molecular determinants of the caspase-promoting activity of Smac/DIABLO and its role in the death receptor pathway. J Biol Chem 275:36152-36157, 2000.

109. Roberts DL, Merrison W, MacFarlane M, Cohen GM. The inhibitor of apoptosis protein-binding domain of Smac is not essential for its proapoptotic activity. J Cell Biol 153:221-228, 2001.

110. Shibata M, Hattori H, Sasaki T, Gotoh J, Hamada J, Fukuuchi Y. Subcellular localization of a promoter and an inhibitor of apoptosis (Smac/DIABLO and XIAP) during brain ischemia/reperfusion. Neuroreport 13:1985-1988, 2002.

111. Okada H, Suh WK, Jin J, Woo M, Du C, Elia A et al. Generation and characterization of Smac/DIABLO-deficient mice. Mol Cell Biol 22:3509-3517, 2002.

112. Syntichaki P, Tavernarakis N. Death by necrosis. Uncontrollable catastrophe, or is there order behind the chaos? EMBO Rep 3:604-609, 2002.

113. Proskuryakov SY, Konoplyannikov AG, Gabai VL. Necrosis: a specific form of programmed cell death? Exp Cell Res 283:1-16, 2003. 
114. Kitanaka C, Kuchino Y. Caspase-independent programmed cell death with necrotic morphology. Tanpakushitsu Kakusan Koso 44:2091-2100, 1999.

115. Syntichaki P, Xu K, Driscoll M, Tavernarakis N. Specific aspartyl and calpain proteases are required for neurodegeneration in $\mathrm{C}$. elegans. Nature 419:939-944, 2002.

116. Saido TC, Sorimachi H, Suzuki K. Calpain: new perspectives in molecular diversity and physiological- pathological involvement. FASEB J 8:814-822, 1994.

117. Bartus RT, Hayward NJ, Elliott PJ, Sawyer SD, Baker KL, Dean RL et al. Calpain inhibitor AK295 protects neurons from focal brain ischemia. Effects of postocclusion intra-arterial administration. Stroke 25:2265-2270, 1994.

118. Kampfl A, Posmantur RM, Zhao X, Schmutzhard E, Clifton GL, Hayes RL. Mechanisms of calpain proteolysis following traumatic brain injury: implications for pathology and therapy: a review and update. J Neurotrauma 14:121-134, 1997.

119. Saito K, Elce JS, Hamos JE, Nixon RA. Widespread activation of calcium-activated neutral proteinase (calpain) in the brain in Alzheimer disease: a potential molecular basis for neuronal degeneration. Proc Natl Acad Sci USA 90:2628-2632, 1993.

120. Yoshida M, Yamashima T, Zhao L, Tsuchiya K, Kohda Y, Tonchev AB et al. Primate neurons show different vulnerability to transient ischemia and response to cathepsin inhibition. Acta Neuropathol (Berl) 104:267-272, 2002.

121. Nakamura Y, Takeda M, Suzuki H, Morita H, Tada K, Hariguchi $\mathrm{S}$ et al. Age-dependent change in activities of lysosomal enzymes in rat brain. Mech Ageing Dev 50:215-225, 1989.

122. Shimizu S, Eguchi Y, Kamiike W, Waguri S, Uchiyama Y, Matsuda $\mathrm{H}$ et al. Retardation of chemical hypoxia-induced necrotic cell death by Bcl-2 and ICE inhibitors: possible involvement of common mediators in apoptotic and necrotic signal transductions. Oncogene 12:2045-2050, 1996.
123. Maas AI. Neuroprotective agents in traumatic brain injury. Expert Opin Investig Drugs 10:753-767, 2001.

124. Allen JW, Knoblach SM, Faden AI. Combined mechanical trauma and metabolic impairment in vitro induces NMDA receptor-dependent neuronal cell death and caspase-3-dependent apoptosis. FASEB $J$ 13:1875-1882, 1999.

125. Faden AI, Fox GB, Fan L, Araldi GL, Qiao L, Wang S et al. Novel TRH analog improves motor and cognitive recovery after traumatic brain injury in rodents. Am J Physiol (Lond) 277: R1196-R1204, 1999.

126. Faden AI. Pharmacotherapeutic treatment approaches for brain and spinal cord trauma. In: Neurotrauma (Narayan RK, Wilberger J, Povlishock JT, eds), pp 1479-1490. New York: McGraw-Hill, 1996.

127. Lavie G, Teichner A, Shohami E, Ovadia H, Leker RR. Longterm cerebroprotective effects of dexanabinol in a model of focal cerebral ischemia. Brain Res 901:195-201, 2001.

128. Callaway JK, Beart PM, Jarrott B, Giardina SF. Incorporation of sodium channel blocking and free radical scavenging activities into a single drug, AM-36, results in profound inhibition of neuronal apoptosis. Br J Pharmacol 132:1691-1698, 2001.

129. Callaway JK, Knight MJ, Watkins DJ, Beart PM, Jarrott B. Delayed treatment with AM-36, a novel neuroprotective agent, reduces neuronal damage after endothelin-1-induced middle cerebral artery occlusion in conscious rats. Stroke 30: 2704-2712, 1999.

130. Faden AI, Fox GB, Di X, Knoblach SM, Cernak I, Mullins P et al. Neuroprotective and nootropic actions of a novel cyclized dipeptide following controlled cortical impact injury in mice. $J$ Cereb Blood Flow Metab 23:355-363, 2003.

131. Faden AI, Knoblach SM, Cernak I, Fan L, Vink R, Roth BL et al. Novel diketopiperazine enhances motor and cognitive recovery after traumatic brain injury in rats and shows neuroprotection in vitro. J Cereb Blood Flow Metab 23:342-354, 2003. 